\title{
Heparin Induces the Mobilization of Heart-Derived Multipotent Mesoangioblasts During Cardiac Surgery With Cardiopulmonary Bypass or Cardiac Catheterization
}

\author{
Yoshihiro Hata, MD; Masayoshi Iwasaki, MD, PhD; Keisuke Fujitaka, MD, PhD; \\ Haengnam Park, MD, PhD; Daisuke Sato, MD, PhD; Chiharu Enoki, MD, PhD; \\ Naoki Minato, MD, PhD; Keita Horitani, MD; Miyuki Nakano, MD; \\ Hiroshi Kishimoto, MD; Kensaku Wada, MD; Masamichi Koyanagi, MD, PhD; \\ Yasushi Adachi, MD, PhD; Yoshihiro Yamamoto, MD, PhD; Andreas M. Zeiher, MD, PhD; \\ Stefanie Dimmeler, PhD; Ichiro Shiojima, MD, $\mathrm{PhD}$
}

\begin{abstract}
Background: We previously identified circulating mesoangioblasts (cMABs), a subset of mesenchymal stem cells that express cardiac mesodermal markers, in patients undergoing cardiac surgery with cardiopulmonary bypass (CPB). We also found that hepatocyte growth factor (HGF) is upregulated during cardiac surgery with CPB in humans, and induces MAB-like cell mobilization in rodents. These results strongly suggest that heparin induced MAB mobilization via HGF upregulation. Here, we tested this hypothesis in patients undergoing cardiac surgery or cardiac catheterization. We also examined whether human cMABs are derived from the heart.
\end{abstract}

Methods and Results: Plasma HGF levels were determined by ELISA. Mononuclear cells isolated from blood samples were cultured on fibronectin-coated dishes, and outgrowing $C M A B$ colonies were counted. We first confirmed that HGF upregulation and CMAB mobilization were observed before the start of $\mathrm{CPB}$, excluding the possibility that $\mathrm{CPB}$ is the primary inducer of cMAB mobilization. We then examined patients undergoing cardiac catheterization and found that heparin significantly increased plasma HGF levels and the number of CMAB colonies in a dose-dependent manner. The results of simultaneous blood sampling from the aortic sinus, coronary sinus, and right atrium were consistent with the notion that human cMABs are derived from the heart.

Conclusions: Human cMABs are mobilized by heparin injection during cardiac surgery or cardiac catheterization, presumably via HGF upregulation.

Key Words: Catheterization; Heparin; Mobilization; Progenitor cells

D espite significant advances in diagnosis and treatment, ${ }^{1-3}$ the prognosis of patients with heart failure still remains poor. ${ }^{4}$ Stem/progenitor cell therapy is a promising therapeutic option for patients suffering from heart failure, and several types of stem/progenitor cells have been tested for cardiac repair. ${ }^{5-7}$ Among these, mesenchymal stem cells (MSCs) differentiate into multiple mesodermal tissues, including endothelial cells and cardiomyocytes, ${ }^{8-12}$ and secrete soluble paracrine factors that contribute to the reduction of fibrosis, the enhancement of endogenous angiogenesis/cardiomyogenesis, and the recruitment of tissue resident stem/progenitor cells. ${ }^{13-15}$ Based on these observations, MSCs have been tested for cardiac

\section{Editorial p 1260}

repair and shown to improve cardiac function and reduce adverse remodeling, not only in animal models but also in humans. ${ }^{16-18}$

Recently, we and others identified a subset of MSCs that express cardiac mesodermal markers from the embryonic aorta, ${ }^{19}$ adult mouse/human heart, ${ }^{20}$ and human blood. ${ }^{21}$ Based on the expression of typical mesenchymal markers and endothelial marker, vascular endothelial growth factor (VEGF) receptor 2(VEGFR2/KDR), these cells were named mesoangioblasts (MABs). ${ }^{22}$ Human circulating MABs

Received March 28, 2017; revised manuscript received August 17, 2017; accepted August 21, 2017; released online September 21, 2017 Time for primary review: 21 days

Department of Medicine II (Y.H., M.I., K.F., H.P., D.S., K.H., M.N., H.K., K.W., Y.Y., I.S.), Department of Cardiovascular Surgery (C.E., N.M.), Kansai Medical University, Hirakata; Kyushu University Beppu Hospital, Beppu (M.K.); Division of Surgical Pathology, Toyooka Hospital, Toyooka (Y.A.), Japan; and Department of Cardiology, Internal Medicine III (A.M.Z.), Institute of Cardiovascular Regeneration, Centre for Molecular Medicine (S.D.), University of Frankfurt, Frankfurt, Germany

Mailing address: Masayoshi Iwasaki, MD, PhD, Department of Medicine II, Kansai Medical University, 2-5-1 Shinmachi, Hirakata 573-1010, Japan. E-mail: iwasakim@hirakata.kmu.ac.jp

ISSN-1346-9843 All rights are reserved to the Japanese Circulation Society. For permissions, please e-mail: cj@j-circ.or.jp 


\begin{tabular}{|c|c|c|c|}
\hline Case no. & Age (years) & Sex & Operation \\
\hline 1 & 74 & $\mathrm{~F}$ & Aortic valve replacement (aortic stenosis) \\
\hline 2 & 80 & M & Aortic valve replacement (aortic stenosis) \\
\hline 3 & 51 & $\mathrm{~F}$ & Aortic valve replacement (aortic regurgitation) \\
\hline
\end{tabular}

Table 2. Patients' Characteristics (Cardiac Catheterization [See Figures 2-4])

\begin{tabular}{|c|c|c|c|c|c|}
\hline & \multicolumn{3}{|c|}{ Dose escalation study } & \multirow{2}{*}{$\begin{array}{l}\text { Time course analysis } \\
(n=10)\end{array}$} & \multirow{2}{*}{$\begin{array}{c}3 \text { points sampling } \\
(n=10)\end{array}$} \\
\hline & $\begin{array}{c}<100 \mathrm{U} / \mathrm{kg} \\
(n=7)\end{array}$ & $\begin{array}{c}200 \mathrm{U} / \mathrm{kg} \\
(\mathrm{n}=11)\end{array}$ & $\begin{array}{c}300 \mathrm{U} / \mathrm{kg} \\
(\mathrm{n}=11)\end{array}$ & & \\
\hline Female sex, n (\%) & $4(57)$ & $8(73)$ & $1(9)$ & $3(30)$ & $6(60)$ \\
\hline Age (years) & $64 \pm 13$ & $59 \pm 17$ & $67 \pm 10$ & $66 \pm 8$ & $75 \pm 8$ \\
\hline LVEF (\%) & $70.7 \pm 4.3$ & $66.2 \pm 9.8$ & $51.8 \pm 20.4$ & $57.2 \pm 16.2$ & $58.7 \pm 14.1$ \\
\hline Hypertension, n (\%) & $1(14)$ & $5(45)$ & $6(55)$ & $3(30)$ & $9(90)$ \\
\hline Diabetes, n (\%) & $1(14)$ & $1(9)$ & $3(27)$ & $5(50)$ & $5(50)$ \\
\hline Dyslipidemia, n (\%) & $3(43)$ & $4(36)$ & $5(45)$ & $7(70)$ & $6(60)$ \\
\hline CKD, n (\%) & $2(29)$ & $0(0)$ & $3(27)$ & $4(40)$ & $4(40)$ \\
\hline Aspirin, n (\%) & $1(14)$ & $0(0)$ & $3(27)$ & $7(70)$ & $6(60)$ \\
\hline Statins, n (\%) & $2(29)$ & $3(27)$ & $3(27)$ & $7(70)$ & $6(60)$ \\
\hline ACEI or ARB, n (\%) & $2(29)$ & $3(27)$ & $7(64)$ & $7(70)$ & $8(80)$ \\
\hline$\beta$-blockers, $\mathrm{n}(\%)$ & $1(14)$ & $2(18)$ & $4(36)$ & $7(70)$ & $1(10)$ \\
\hline
\end{tabular}

Mean \pm SD. ACEI, angiotensin-converting enzyme inhibitor; ARB, angiotensin-receptor blocker; CKD, chronic kidney disease; eGFR, estimated glomerular filtration rate $<60 \mathrm{~mL} / \mathrm{min} / 1.73 \mathrm{~m}^{2} ; \mathrm{LVEF}$, left ventricular ejection fraction.

\begin{tabular}{|lll|}
\hline $\begin{array}{c}\text { Table 3. List of Primers Used in This Study } \\
\text { Primer }\end{array}$ & \multicolumn{1}{c|}{ Sequence } \\
Nkx2.5 & Forward & CAC CGG CCA AGT GTG CGT CT \\
& Reverse & CCG CGT TGT CCG CCT CTG \\
\multirow{4}{*}{ Mef2C } & Forward & GAC GGG TCA CTA TCT GTG C \\
& Reverse & CAC TAC CTG AAG GAG CTG C \\
Tbx5 & Forward & CAT CTG GTT GGT TTT CAG CC \\
& Reverse & CGG ATG ACA AAG CAA CTA TCC \\
Oct3/4 & Forward & CCA CAG CTG GGA GAG GGA AT \\
& Reverse & CAA CTC CGT GCA CAG AGT GG \\
Sox2 & Forward & GAA CAT GTG TAA GCT GCG GC \\
& Reverse & TTC TGG CGC CGG TTA CAG AA \\
KIf4 & Forward & AGA TGC ACA ACT CGG AGA TCA GC \\
& Reverse & GCC GTT CAT GTG CGC GTA ACT GTC \\
cMyc & Forward & CCC ACA TTA ATG AGG CAG CC \\
& Reverse & TGG GGG AAG TCG CTT CAT GT \\
Gapdh & Forward & AAC GAC AGC AGC TCG CCC AA \\
& Reverse & TTG AGG ACC AGT GGG CTG TG \\
& Forward & GAA GGT GAA GGT CGG AGT C \\
& Reverse & GAA GAT GGT GAT GGG ATT TC
\end{tabular}

(cMABs) are distinct from hematopoietic progenitor cells and early/late endothelial progenitor cells because cMABs lack the expression of CD45, CD34, CD133, and platelet endothelial cell adhesion molecule-1 (PECAM-1). ${ }^{21}$ Human cMABs are clonally expandable and can differentiate into endothelial cells, smooth muscle cells, and cardiomyocytes. ${ }^{21}$ Moreover, human cMABs also secrete several growth factors that are favorable for repair of the injured heart, ${ }^{21}$ and cMAB transplantation enhances the functional recovery after acute myocardial infarction and hindlimb ischemia in mice. ${ }^{21,23}$
cMABs were originally isolated from patients undergoing cardiac surgery with cardiopulmonary bypass (CPB), although $\mathrm{cMAB}$ colonies were not obtained in patients undergoing off-pump coronary bypass surgery. ${ }^{21,23} \mathrm{We}$ also found that hepatocyte growth factor (HGF) is upregulated during cardiac surgery in humans, and induces MAB-like cell mobilization in rodents. ${ }^{23}$ Because heparin is generally used during $\mathrm{CPB}$ and well known to upregulate the plasma HGF concentration, ${ }^{24}$ these results strongly suggest that heparin induces $\mathrm{cMAB}$ mobilization via $\mathrm{HGF}$ upregulation. In this study, we tested this hypothesis in patients undergo- 


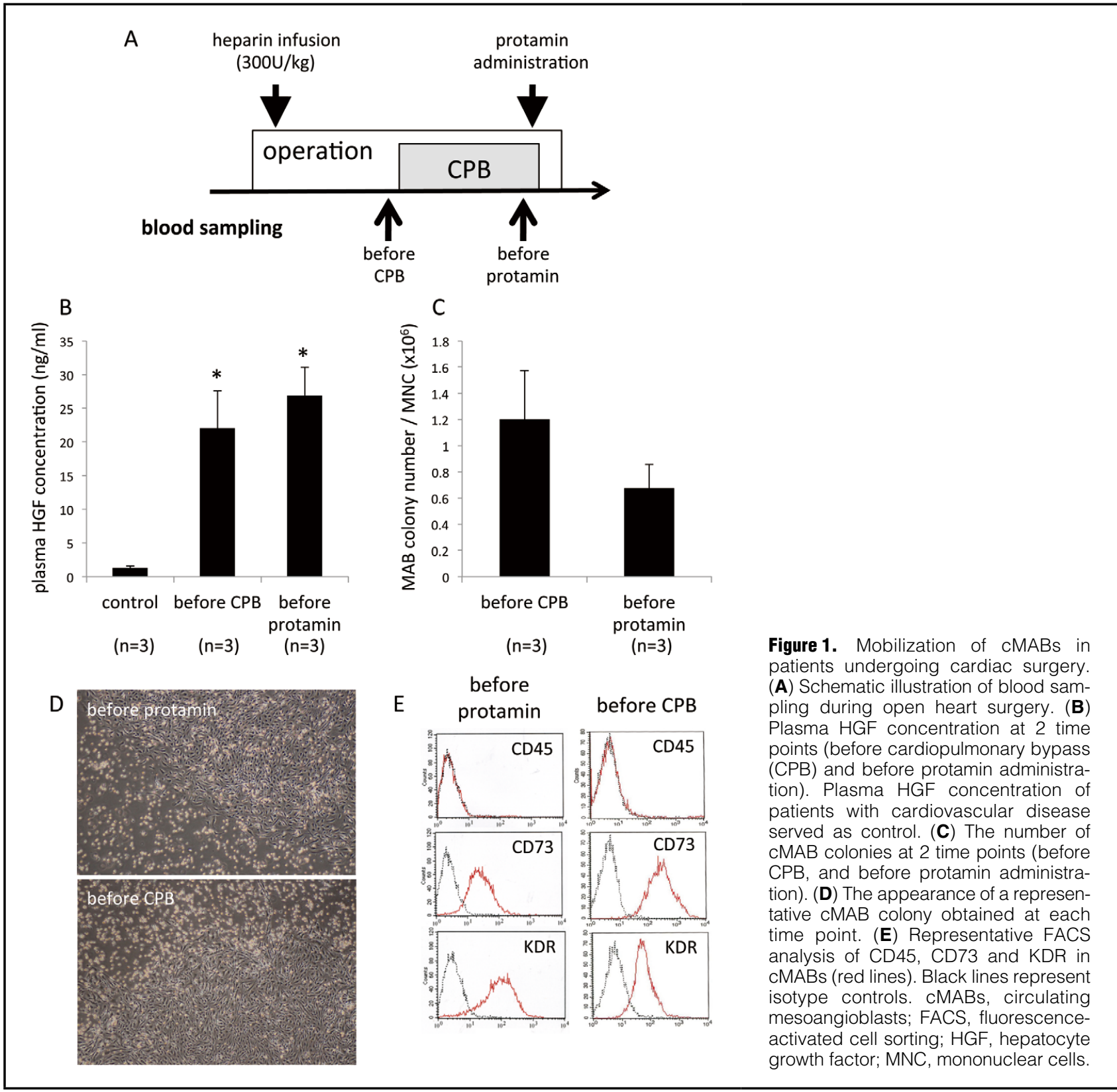

ing cardiac surgery or cardiac catheterization. We also examined whether human cMABs are derived from the heart.

\section{Methods}

\section{Cell Isolation and Culture}

Blood samples were collected from patients undergoing either cardiac surgery with CPB or cardiac catheterization. Written informed consent was given by each patient. Cell preparation was done as previously described. ${ }^{21,23}$ In brief, blood-derived mononuclear cells (MNCs) were isolated by Ficoll density gradient centrifugation and plated on fibronectin-coated dishes in EBM medium with supplemental growth factors and $20 \%$ fetal bovine serum. After 7 days in culture, non-adherent cells were discarded and attached cells were cultured for another 7 days with EBM medium. On day 15 , the number of colonies was counted, and cells were detached using $0.25 \%$ Trypsin-EDTA (Gibco) and seeded at $5 \times 10^{4}$ cells $/ \mathrm{mL}$ on fibronectin-coated dishes. At $80 \%$ confluence, cells were resuspended at $5 \times 10^{4}$ cells $/ \mathrm{mL}$ and used for following analyses. The Ethics Review Board of Kansai Medical University approved the protocol, and the study was conducted in accordance with the Declaration of Helsinki. CPB and catheterization patients' characteristics are summarized in Table $\mathbf{1}$ and Table 2, respectively.

\section{Flow Cytometry}

The following reagents were used for fluorescence-activated cell sorting (FACS): phycoerythrin (PE)-conjugated antiCD34, CD44, CD45, CD73, PE-conjugated streptavidin, and isotype-matched PE-conjugated mouse immunoglobulins (BD Biosciences); and PE-conjugated anti-CD144, KDR, and biotinylated anti-c-Met (R\&D). Samples were analyzed by BD FACS Calibur (BD Biosciences). 


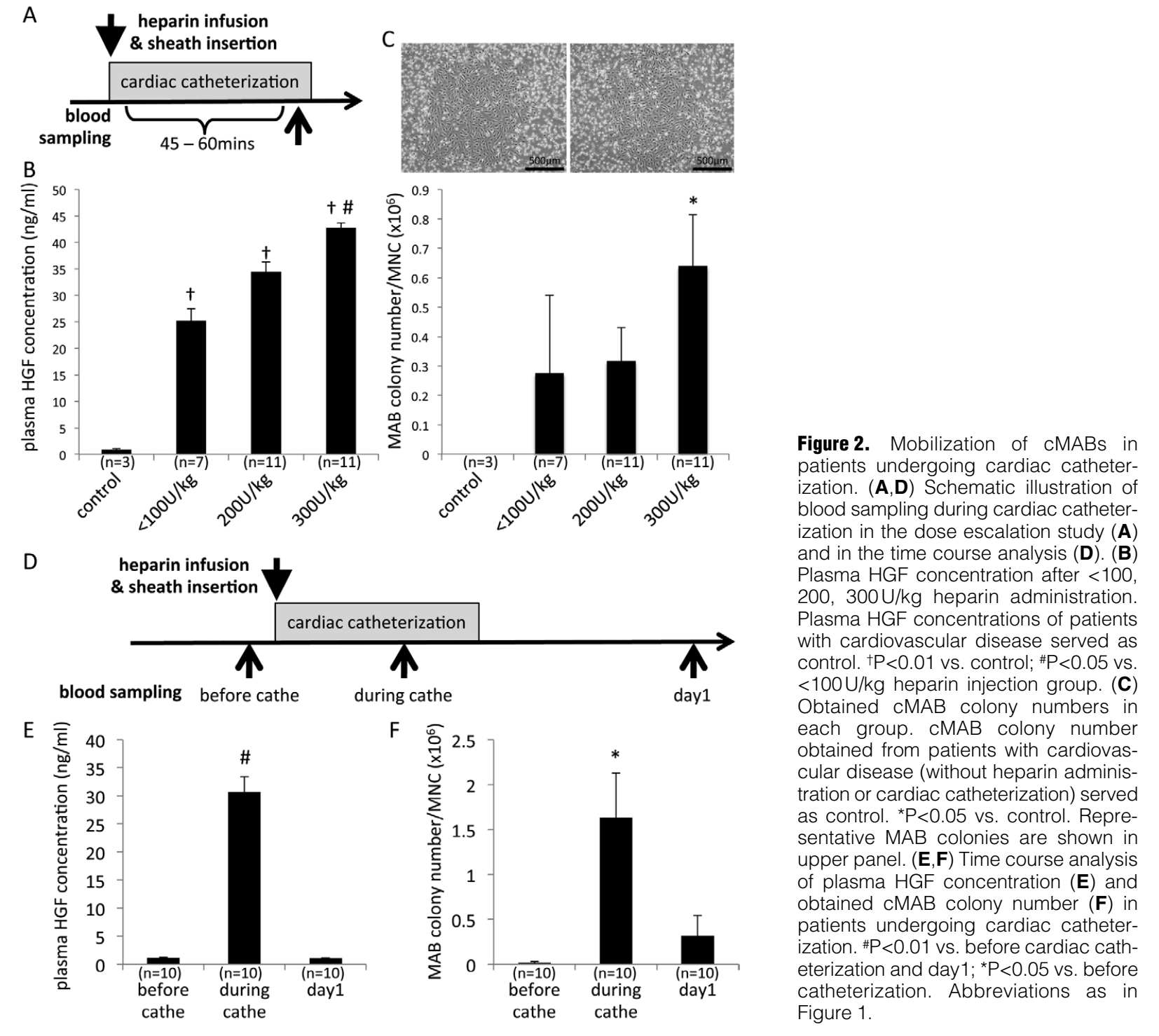

\section{RT-PCR}

Total RNAs were isolated using TRIzol (Invitrogen). RNA was subjected to RT-PCR using SuperScript First Strand Synthesis System (Invitrogen). Primer sequences are listed in Table 3.

\section{ELISA}

Quantification of plasma HGF was performed according to the manufacturer's instructions. ELISA kits were purchased from R\&D.

\section{Immunostaining}

Cells were fixed with $4 \%$ paraformaldehyde. After permeabilization with $0.2 \%$ saponin (Sigma), cells were incubated with anti-Nkx2.5 and anti-Oct3/4 antibodies (R\&D) conjugated with Alexa Fluor 488 using a Monoclonal Antibody Labeling Kit (Molecular Probes). Images were recorded by confocal microscope (LSM510-META, Carl Zeiss).

\section{Statistical Analysis}

Data are expressed as mean \pm SEM. For comparison of 2 groups, two-tailed Student's t-test (paired groups) was used. For comparison of $\geq 3$ groups, ANOVA with post-hoc testing was used. Statistical significance was assumed at a value of $\mathrm{P}<0.05$. All statistical analyses were performed with SPSS (Version 19.0, IBM, Armonk, NY, USA).

\section{Results}

\section{Heparin as Primary Inducer of cMAB Mobilization During Cardiac Surgery}

In our previous study $\mathrm{cMAB}$ colonies were obtained from patients undergoing cardiac surgery with $\mathrm{CPB}$ but not from patients undergoing off-pump coronary bypass surgery. ${ }^{23}$ To test whether $\mathrm{CPB}$ contributes to $\mathrm{cMAB}$ mobilization, we obtained blood samples from 3 patients undergoing aortic valve replacement at 2 time points: before the start of CPB and at the end of CPB (Figure 1A). The number of obtained cMAB colonies was not different 
A

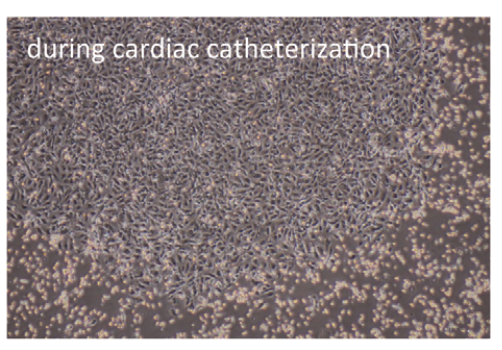

C

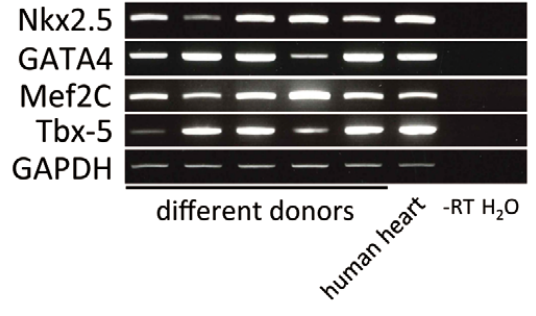

$E$

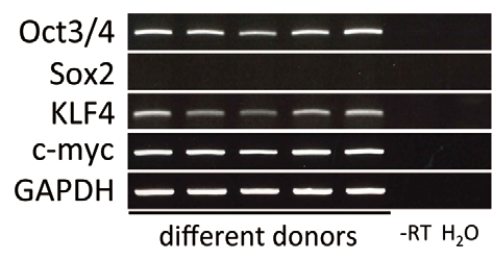

B
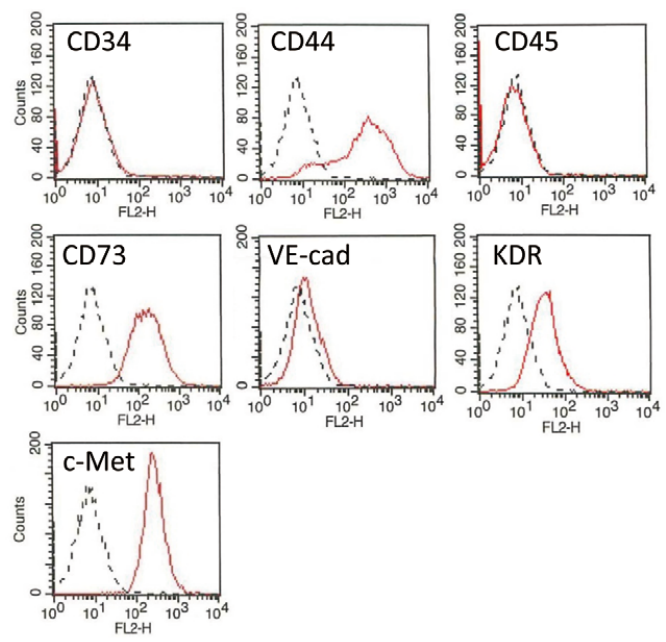

D

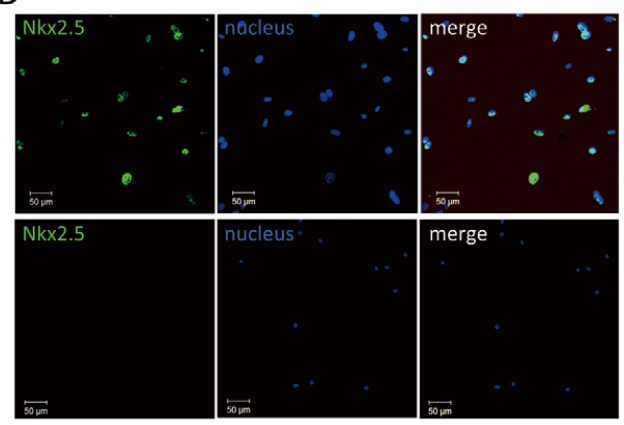

F
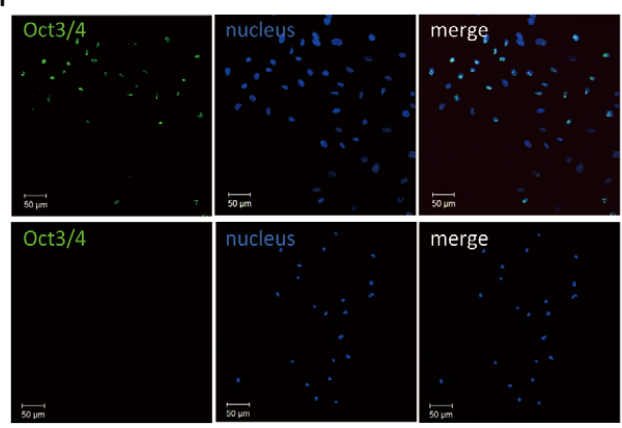

merge
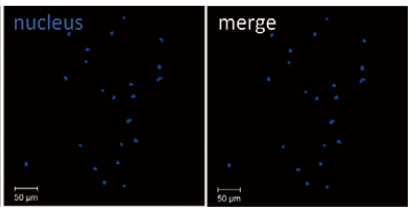

Figure 3. Characteristics of $c M A B s$ obtained from patients undergoing cardiac catheterization. (A) Representative cMAB colony. (B) Representative FACS staining of CD34, CD44, CD45, CD73, VE-cadherin, KDR and c-Met in cMABs (red). Black lines represent isotype controls. (C) RT-PCR analysis of Nkx2.5, GATA4, MEF2C, Tbx5 and GAPDH in cMABs. Human heart and -RT and $\mathrm{H}_{2} \mathrm{O}$ served as positive and negative controls, respectively. (D) Immunocytochemistry of cMABs showing nuclear localization of Nkx2.5 (green). Peripheral blood-derived MNC served as control. (E) RT-PCR analysis of Oct3/4, SOX2, KLF-4, cMyc and GAPDH in cMABs. - RT and $\mathrm{H}_{2} \mathrm{O}$ served as negative controls. (F) Immunocytochemistry of cMABs showing nuclear localization of Oct3/4 (green). Peripheral blood-derived MNCs served as control. RT-PCR, reverse transcription polymerase chain reaction. Other abbreviations as in Figure 1.

between these time points (Figure 1C), and plasma HGF concentration at these 2 time points was upregulated to the comparable level when compared with the control (Figure 1B). The appearance of cMABs obtained before the start of CPB was essentially the same as that of cMABs obtained at the end of CPB (Figure 1D), and the expression pattern of cell surface markers (CD45- ${ }^{-}$D $\left.73^{+} \mathrm{KDR}^{+}\right)$was identical between cMABs obtained at these 2 time points
(Figure 1E). Taken together with previous observations that heparin upregulates plasma HGF concentration and that HGF mobilizes MAB-like cells in rodents, ${ }^{23,24}$ these data strongly suggested that heparin induced cMAB mobilization via $\mathrm{HGF}$ upregulation and that $\mathrm{CPB}$ did not play a major role in cMAB mobilization during cardiac surgery. 


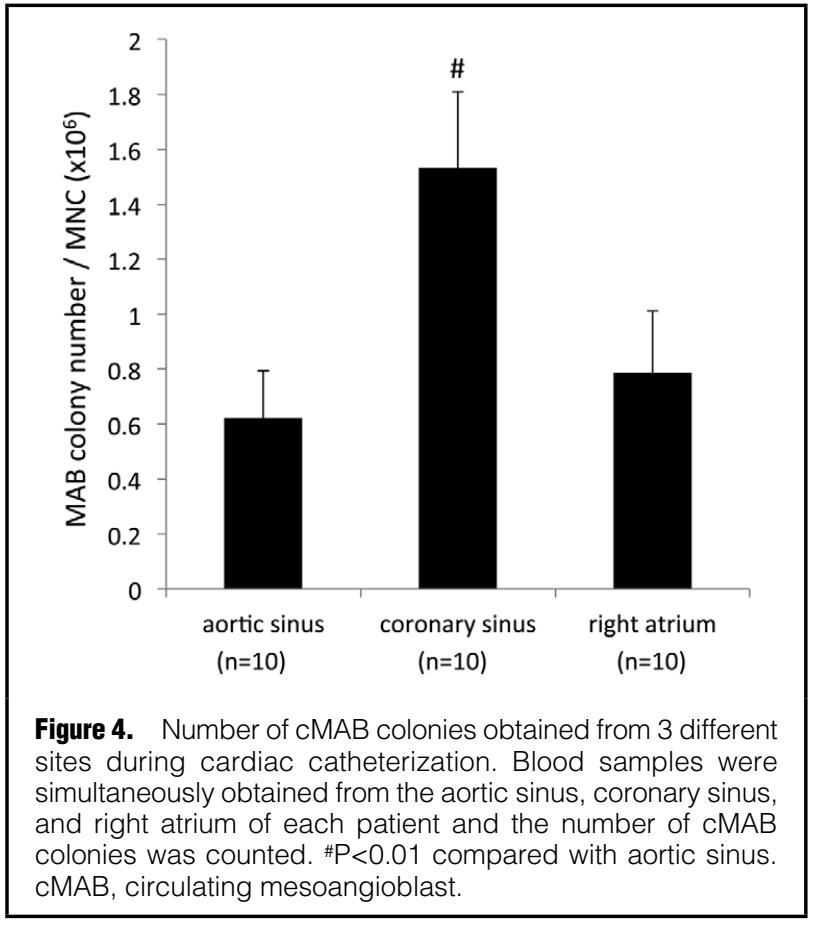

\section{Heparin Induces cMAB Mobilization During Cardiac Catheterization}

In order to examine the role of heparin in cMAB mobilization in a different context, we obtained blood samples from patients undergoing cardiac catheterization, 45-60 min after heparin infusion (Figure 2A). Heparin was administered at the dose of $<100(n=7), 200(n=11)$ or $300 \mathrm{U} / \mathrm{kg}(\mathrm{n}=11)$ at the time of sheath insertion. Consistent with the previous finding, ${ }^{24}$ heparin dose-dependently increased the plasma HGF concentration (Figure 2B), and this was associated with cMAB mobilization (Figure 2C). We also obtained blood samples at 3 time points from another 10 patients undergoing cardiac catheterization: before, during, and 1 day after cardiac catheterization (Figure 2D). Upregulation of plasma HGF concentration was transient and the time course of plasma HGF concentration paralleled the number of cMAB colonies obtained (Figure 2E,F). These data were consistent with the notion that heparin induces cMAB mobilization via the upregulation of plasma HGF.

The appearance of colonies obtained from patients undergoing cardiac catheterization was similar to that of cMABs obtained during cardiac surgery (Figure 3A), Flow cytometric analysis revealed that these cells lacked expression of the hematopoietic progenitor cell markers CD45 and CD34 and expressed the mesenchymal markers CD44 and CD73, the early endothelial marker KDR and the HGF-receptor c-Met (Figure 3B). RNA analysis revealed the expression of cardiac mesoderm marker genes ( $\mathrm{Nkx} 2.5$, GATA4, MEF2C, and Tbx5) and pluripotency genes (Oct3/4, KLF-4, and c-Myc) (Figure 3C,E). Nuclear expression of $\mathrm{Nkx} 2.5$ and Oct3/4 proteins was confirmed by immunohistochemistry (Figure 3D,F). Thus, heparin induced $\mathrm{cMAB}$ mobilization during cardiac catheterization presumably by increasing plasma HGF levels.

\section{Human cMABs Derive From the Heart}

We next tested whether human cMABs mobilized during cardiac catheterization are derived from the heart. Blood samples were simultaneously obtained from the aortic sinus, coronary sinus, and right atrium 45-60 min after heparin injection, and cMAB colonies were cultured. We obtained a significantly higher number of $\mathrm{cMAB}$ colonies from the coronary sinus than from the aortic sinus (Figure 4). These data were consistent with the notion that human cMABs are predominantly derived from the heart during cardiac catheterization.

\section{Discussion}

The results of the present study demonstrated that (1) heparin mobilized human heart-derived MABs during cardiac catheterization, and (2) the rapid upregulation of plasma HGF after heparin injection was the likely mechanism of cMAB mobilization.

MSCs are multipotent progenitor cells originally identified in the bone marrow, ${ }^{25}$ although were later found to reside in multiple adult organs or tissues. ${ }^{26}$ MABs are a subset of MSCs. They were originally isolated from mouse embryonic aorta, ${ }^{19}$ and subsequently identified from the adult mouse and human hearts. ${ }^{20}$ Furthermore, MABs are mobilized into circulation during cardiac surgery with CPB. ${ }^{21,23}$ cMABs coexpress mesenchymal stem cell markers and cardiac mesodermal markers (e.g., Nkx2.5, MEF2C, and GATA4), have high proliferative capacity in culture, are capable of differentiation into cardiac myocytes, smooth muscle cells, and endothelial cells, and promote functional recovery after myocardial infarction. ${ }^{21}$ Moreover, the C-CURE trial demonstrated that bone marrow-derived MSCs exposed to a cardiogenic cocktail express cardiac mesodermal markers and that this cardiopoietic stem cell therapy had beneficial effects on the clinical outcome of patients with heart failure. ${ }^{18}$ These results collectively suggest that cMABs are a potential cell source for cardiac repair.

In the present study we found that heparin induced cMAB mobilization during cardiac catheterization. Heparin increases plasma HGF by releasing HGF bound to the extracellular matrix. ${ }^{27}$ Indeed, HGF upregulation by heparin occurs rapidly without a significant increase in the HGF mRNA level. ${ }^{24,28}$ Together with our previous observations that HGF is upregulated during cardiac surgery with $\mathrm{CPB}$ and that HGF mobilizes MAB-like cells in rodents, the results of our present study are consistent with the notion that heparin induces $\mathrm{CMAB}$ mobilization in humans via HGF upregulation. A feasible method for cell isolation is critical for the clinical application of cell therapy. In this regard, we believe that our study provides a practical approach for the establishment of cardiac repair using cMABs.

Stem/progenitor cell mobilization has been extensively studied using hematopoietic stem cells (HSCs). The SDF- $1 \alpha$-CXCR 4 axis is a key signaling axis for the retention, migration and mobilization of HSCs and the disruption of this signaling axis by G-CSF or the CXCR4 inhibitor AMD3000 facilitate the egress of HSCs from their niche..$^{29-31}$ It was also reported that CXCR4 inhibitor administration to mice pretreated with VEGF resulted in MSC mobilization. Our results indicated that the HGFreceptor c-Met was expressed in mobilized cMABs, and it was previously shown that HGF stimulates migration of MSCs. ${ }^{32}$ However, the mechanistic basis of cMAB mobilization by HGF is unclear at present and awaits further investigation. 
Because MABs from the adult mouse and human heart have been identified ${ }^{20}$ it is plausible that cMABs mobilized by heparin during cardiac catheterization are also derived from the heart, and the results of our blood sampling study were consistent with this notion. It was previously shown that the perivascular region is a site of MSCs in multiple human organs. ${ }^{33}$ MABs are also known as vessel-associated progenitor cells, ${ }^{19,34}$ and $\mathrm{CD}^{2} 3^{+}$cells have been detected in the perivascular region of the human heart. ${ }^{23}$ Taken together, the data strongly suggest that human cMABs are mobilized from a perivascular niche of the heart in response to heparin injection during cardiac catheterization.

It should be noted that the method of isolating cMABs is similar to that used for the isolation of previously described late outgrowth endothelial progenitor cells/outgrowth endothelial cells (OECs). The reason why cMABs but not OECs were the predominant cell type obtained in our study is not clear but presumably related to cMABs having a higher proliferative capacity than OECs and to MABs being mobilized by heparin injection such that they constitute the predominant cell population after several passages.

In summary, our study demonstrated that human MABs, a subset of MSCs, can be mobilized from the heart by heparin during cardiac catheterization. The identification of an efficient and reproducible protocol for the mobilization of human cardiovascular progenitors may lead to the establishment of a novel therapeutic option for patients with heart disease.

\section{Name of Grant}

This work is supported by JSPS KAKENHI Grant Number 25460917.

\section{References}

1. Flather MD, Yusuf S, Køber L, Pfeffer M, Hall A, Murray G, et al. Long-term ace-inhibitor therapy in patients with heart failure or left-ventricular dysfunction: A systematic overview of data from individual patients: ACE-inhibitor myocardial infarction collaborative group. Lancet 2000; 355: 1575-1581.

2. Packer M, Coats AJ, Fowler MB, Katus HA, Krum H, Mohacsi $\mathrm{P}$, et al; Carvedilol Prospective Randomized Cumulative Survival Study Group. Effect of carvedilol on survival in severe chronic heart failure. N Engl J Med 2001; 344: 1651-1658.

3. Pitt B, Zannad F, Remme WJ, Cody R, Castaigne A, Perez A, et al. The effect of spironolactone on morbidity and mortality in patients with severe heart failure: Randomized aldactone evaluation study investigators. N Engl J Med 1999; 341: 709-717.

4. Jhund PS, Macintyre K, Simpson CR, Lewsey JD, Stewart S, Redpath A, et al. Long-term trends in first hospitalization for heart failure and subsequent survival between 1986 and 2003: A population study of 5.1 million people. Circulation 2009; 119: $515-523$.

5. Ptaszek LM, Mansour M, Ruskin JN, Chien KR. Towards regenerative therapy for cardiac disease. Lancet 2012; 379: 933-942.

6. Laflamme MA, Murry CE. Heart regeneration. Nature 2011; 473: $326-335$.

7. Broughton KM, Sussman MA. Myocardial regeneration for humans: Modifying biology and manipulating evolution. Circ $J$ 2017; 81: 142-148.

8. Caplan AI. Mesenchymal stem cells. J Orthop Res 1991; 9: 641650.

9. Pittenger MF, Martin BJ. Mesenchymal stem cells and their potential as cardiac therapeutics. Circ Res 2004; 95: 9-20.

10. Pittenger MF, Mackay AM, Beck SC, Jaiswal RK, Douglas R, Mosca JD, et al. Multilineage potential of adult human mesenchymal stem cells. Science 1999; 284: 143-147.

11. Fukuda K. Progress in myocardial regeneration and cell transplantation. Circ J 2005; 69: 1431-1446.

12. Choi SH, Jung SY, Kwon SM, Baek SH. Perspectives on stem cell therapy for cardiac regeneration: Advances and challenges. Circ J 2012; 76: 1307-1312.

13. Caplan AI, Dennis JE. Mesenchymal stem cells as trophic medi- ators. J Cell Biochem 2006; 98: 1076-1084.

14. Kinnaird T, Stabile E, Burnett MS, Lee CW, Barr S, Fuchs S, et al. Marrow-derived stromal cells express genes encoding a broad spectrum of arteriogenic cytokines and promote in vitro and in vivo arteriogenesis through paracrine mechanisms. Circ Res 2004; 94: $678-685$.

15. Hatzistergos KE, Quevedo H, Oskouei BN, Hu Q, Feigenbaum GS, Margitich IS, et al. Bone marrow mesenchymal stem cells stimulate cardiac stem cell proliferation and differentiation. Circ Res 2010; 107: 913-922.

16. Karantalis V, Hare JM. Use of mesenchymal stem cells for therapy of cardiac disease. Circ Res 2015; 116: 1413-1430.

17. Hare JM, Fishman JE, Gerstenblith G, DiFede Velazquez DL, Zambrano JP, et al. Comparison of allogeneic vs. autologous bone marrow-derived mesenchymal stem cells delivered by transendocardial injection in patients with ischemic cardiomyopathy: The POSEIDON randomized trial. JAMA 2012; 308: $2369-$ 2379.

18. Bartunek J, Behfar A, Dolatabadi D, Vanderheyden M, Ostojic M, Dens J, et al. Cardiopoietic stem cell therapy in heart failure: The C-CURE (Cardiopoietic Stem Cell Therapy in Heart Failure) multicenter randomized trial with lineage-specified biologics. $J$ Am Coll Cardiol 2013; 61: 2329-2338.

19. Minasi MG, Riminucci M, De Angelis L, Borello U, Berarducci $\mathrm{B}$, Innocenzi A, et al. The meso-angioblast: A multipotent, selfrenewing cell that originates from the dorsal aorta and differentiates into most mesodermal tissues. Development 2002; 129: 2773-2783.

20. Gálvez BG, Covarello D, Tolorenzi R, Brunelli S, Dellavalle A, Crippa S, et al. Human cardiac mesoangioblasts isolated from hypertrophic cardiomyopathies are greatly reduced in proliferation and differentiation potency. Cardiovasc Res 2009; 83: 707716.

21. Koyanagi M, Iwasaki M, Rupp S, Tedesco FS, Yoon CH, Boeckel JN, et al. Sox2 transduction enhances cardiovascular repair capacity of blood-derived mesoangioblasts. Circ Res 2010; 106: $1290-1302$.

22. Cossu G, Bianco P. Mesoangioblasts: Vascular progenitors for extravascular mesodermal tissues. Curr Opin Genet Dev 2003; 13: $537-542$.

23. Iwasaki M, Koyanagi M, Kossmann H, Monsefi N, Rupp S, Trauth J, et al. Hepatocyte growth factor mobilizes non-bone marrow-derived circulating mesoangioblasts. Eur Heart J 2011; 32: $627-636$.

24. Matsumori A, Ono K, Okada M, Miyamoto T, Sato Y, Sasayama S. Immediate increase in circulating hepatocyte growth factor/scatter factor by heparin. J Mol Cell Cardiol 1998; 30: 2145-2149.

25. Friedenstein AJ, Chailakhjan RK, Lalykina KS. The development of fibroblast colonies in monolayer cultures of guinea-pig bone marrow and spleen cells. Cell Tissue Kinet 1970; 3: 393-403.

26. da Silva Meirelles L, Chagastelles PC, Nardi NB. Mesenchymal stem cells reside in virtually all post-natal organs and tissues. $J$ Cell Sci 2006; 119: 2204-2213.

27. Taniguchi T, Toi M, Tominaga T. Rapid induction of hepatocyte growth factor by heparin. Lancet 1994; 344: 470.

28. Matsumoto K, Tajima H, Okazaki H, Nakamura T. Heparin as an inducer of hepatocyte growth factor. J Biochem 1993; 114: $820-826$.

29. Cottler-Fox MH, Lapidot T, Petit I, Kollet O, DiPersio JF, Link $\mathrm{D}$, et al. Stem cell mobilization. Hematology Am Soc Hematol Educ Program 2003: 419-437.

30. Petit I, Szyper-Kravitz M, Nagler A, Lahav M, Peled A, Habler $\mathrm{L}$, et al. G-CSF induces stem cell mobilization by decreasing bone marrow SDF-1 and up-regulating CXCR4. Nat Immunol 2002; 3: 687-694.

31. Liles WC, Broxmeyer HE, Rodger E, Wood B, Hübel K, Cooper $\mathrm{S}$, et al. Mobilization of hematopoietic progenitor cells in healthy volunteers by AMD3100, a CXCR4 antagonist. Blood 2003; 102: $2728-2730$.

32. Neuss S, Becher E, Wöltje M, Tietze L, Jahnen-Dechent W. Functional expression of HGF and HGF receptor/c-met in adult human mesenchymal stem cells suggests a role in cell mobilization, tissue repair, and wound healing. Stem Cells 2004; 22: 405-414.

33. Crisan M, Yap S, Casteilla L, Chen CW, Corselli M, Park TS, et al. A perivascular origin for mesenchymal stem cells in multiple human organs. Cell Stem Cell 2008; 3: 301-313.

34. Le Grand F, Auda-Boucher G, Levitsky D, Rouaud T, Fontaine-Pérus J, Gardahaut MF. Endothelial cells within embryonic skeletal muscles: A potential source of myogenic progenitors. Exp Cell Res 2004; 301: 232-241. 